Research Article

\title{
Study of Mechanical Property of Rock under Uniaxial Cyclic Loading and Unloading
}

\author{
Hongjun Guo $\mathbb{D}$, ${ }^{1}$ Ming Ji $\mathbb{D},{ }^{1}$ Yidong Zhang $\mathbb{D}^{2}$, and Meng Zhang $\mathbb{D}^{1}$ \\ ${ }^{1}$ Key Laboratory of Deep Coal Resource Mining, Ministry of Education of China, School of Mines, \\ China University of Mining \& Technology, Xuzhou 221116, China \\ ${ }^{2}$ State Key Laboratory of Coal Resources and Safe Mining, China University of Mining \& Technology, Xuzhou 221116, China
}

Correspondence should be addressed to Ming Ji; jiming@cumt.edu.cn

Received 20 July 2018; Accepted 18 September 2018; Published 21 October 2018

Guest Editor: Dengke Wang

Copyright ( $\odot 2018$ Hongjun Guo et al. This is an open access article distributed under the Creative Commons Attribution License, which permits unrestricted use, distribution, and reproduction in any medium, provided the original work is properly cited.

\begin{abstract}
Through studying the mechanics, energy, and deformation features of rock under uniaxial cyclic loading and unloading, the findings are as follows: (1) under cyclic loading and unloading, the curve of stress and strain for loading and unloading in every cycle was not superposition reciprocally but formed an acutifoliate hysteresis loop. The distribution of the hysteresis loop became denser with the cycles and moved toward the direction of strain increasing. (2) The area of the hysteresis loop indicated the inner damage degree of rock. And the hysteresis energy accumulated was stronger; the damage of rock was more serious. Furthermore, the hysteresis energy grew linearly along with load, and the hysteresis energy accumulated had a trend exponential growth with cycle continuing. (3) The elasticity modulus grew in the form of logarithm as a whole. In each cycle, elasticity modulus for unloading was greater than that for loading. When it exceeded a certain value, elasticity modulus for reloading was less than elasticity modulus for unloading. (4) The cyclic loading and unloading had a strength impact that was gradually stronger and stronger as the cycle went on the sample of rock.
\end{abstract}

\section{Introduction}

In the field of rock engineering, the cyclic load is often encountered. However, the laws in the strength and deformation of rock under the cyclic loading are significantly different from those under the static load. In order to better understand and master the mechanical properties and deformation laws of rock under the cyclic loading, a lot of research work has been done by scholars at home and abroad.

Liu et al. [1] studied the damping characteristics of rock under the cyclic loading and obtained the relationship between the dynamic elastic modulus and the damping ratio and the dynamic load. The mechanical properties and hysteresis evolution of sandstone under uniaxial compression was studied by Xu et al. [2,3]. They found that the load level has little effect on the curve of stress-strain. The loading and unloading deformation modulus does not change with the cycles, but the loading strain rate affects the elastic modulus and deformation characteristics of the rock. Yang et al. [4] pointed out that, under the uniaxial cyclic loading, the fatigue failure threshold of $3 \#$ coal seam in Baodian Coal Mine does not exceed $81 \%$ of its uniaxial compressive strength. When it is less than this value, it also produces a certain degree fatigue damage with cyclical loading and unloading. The uniaxial and triaxial cyclic loading failure tests of sandstone were carried out by Xi et al. [5], who told us that the rock modulus decreases with the increase of the cycles, and its attenuation amplitude and rock damage increase with the increase of the cycles. Su and Yang [6] carried out uniaxial cyclic loading and unloading tests on the marble samples with different grains. And the results showed that (1) when the axial stress is less than $40 \%$ of the ultimate bearing capacity, the average Young's modulus during loading and unloading occurs at different degrees' increase with the stress; (2) the loading average Young's modulus increases slightly before yield, but the unloading average Young's modulus remains basically unchanged; and (3) at the yield failure stage, the loading and unloading average Young's modulus decreases with the yield stress. A uniaxial cyclic loading and unloading test on sandstone samples with 
prefabricated fractures was done. Xu et al. [7] found that the stress level of cyclic loading is an important factor affecting the fatigue characteristics of intact rock and intermittent fractured rock mass, and the fatigue deformation and the upper limit stress of the periodic load are hardly affected by the integrity of the sample in the postpeak region of the static stress-strain curve. Bagde and Petros [8] carried out the fatigue tests of tight sandstone under dynamic uniaxial cyclic loading. It showed that the fatigue strength of the rock decreases and the modulus increases with the increasing frequency of dynamic load. Under the given energy condition, the rock is more prone to yielding at low frequencies and low amplitudes. Eberhardt et al. $[9,10]$ analyzed the mechanical properties of fracture damage of brittle rock in the process of uniaxial cyclic loading and unloading, and further studied the propagation conditions and fracture criteria of microcracks. The strength and deformation characteristics of rock under the complex stress path were studied by Yu et al. [11, 12], and the marble's strengthening ratio of peak strength under the condition of uniaxial cyclic loading and unloading was proposed. $\mathrm{Xu}$ et al. [13] conducted an experimental research on the skarn's mechanical properties of uniaxial cyclic loading and unloading and analyzed its acoustic emission characteristics. The strength and deformation characteristics, elastic parameter estimation, and damping characteristics of rock under uniaxial compression cycle loading and unloading conditions were also studied by Wang et al. [14-16].

The above research results showed that the deformation characteristics of different rocks under cyclic loading are significantly different, which is not only related to the differences in individual characteristics but also inextricably linked to the ways of loading and unloading. In this paper, the mechanical properties and deformation laws of rock are analyzed by the uniaxial cyclic loading and unloading test.

\section{Uniaxial Loading and Unloading Test and Data Analysis}

In this test, the red sandstone with relatively good integrity and uniformity was selected. According to the international standard of the rock test sample size, it is processed into a cylinder with a diameter of $50 \mathrm{~mm}$ and a height of $100 \mathrm{~mm}$, and the parallelism of the upper and lower surfaces is less than $0.02 \mathrm{~mm}$. The test was carried out on the MTS815.02 electrohydraulic servo rock mechanics test machine of China University of Mining and Technology. The stress control method was used. The axial pressure $\sigma 1$ is increased or decreased at a rate of $0.25 \mathrm{MPa} / \mathrm{s}$, and the stress path is $0 \longrightarrow 10 \longrightarrow 0 \longrightarrow 20 \longrightarrow \ldots \longrightarrow 90 \longrightarrow 0 \longrightarrow 100 \mathrm{MPa}$, as shown in Figure 1.

The test was repeated four times, and a large amount of data were collected. Since the conclusions of the four groups of experiments are consistent, it was explained on the basis of B group data.

2.1. Hysteresis Loop and Energy Deformation Characteristics. It is known from Figures 2 and 3 that the cyclic loading and unloading curves of the rock samples do not coincide in the

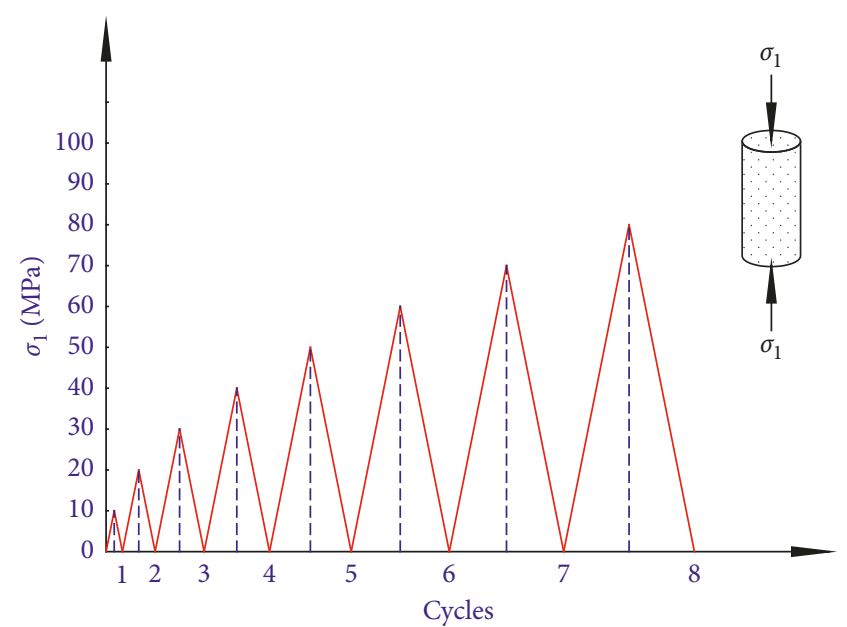

Figure 1: Stress path of the uniaxial loading and unloading test.

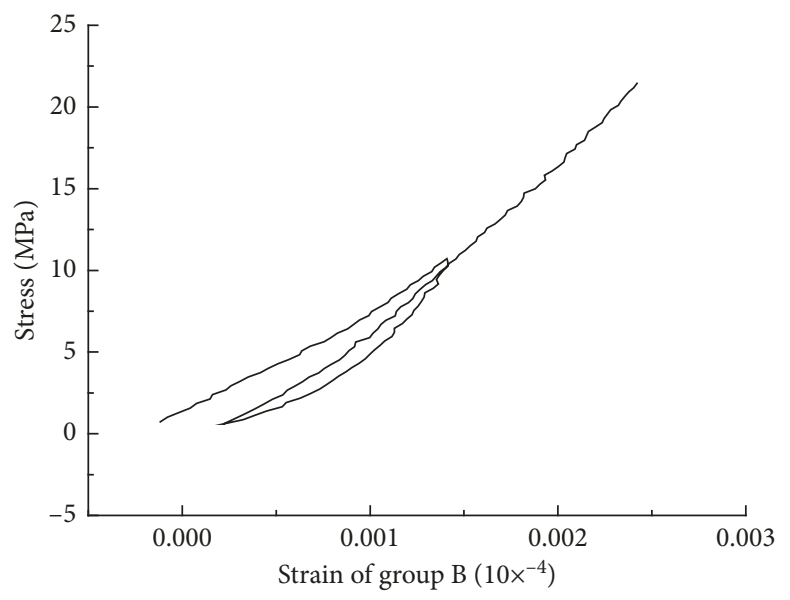

FIgURE 2: Curve of stress and strain in the first cycle.

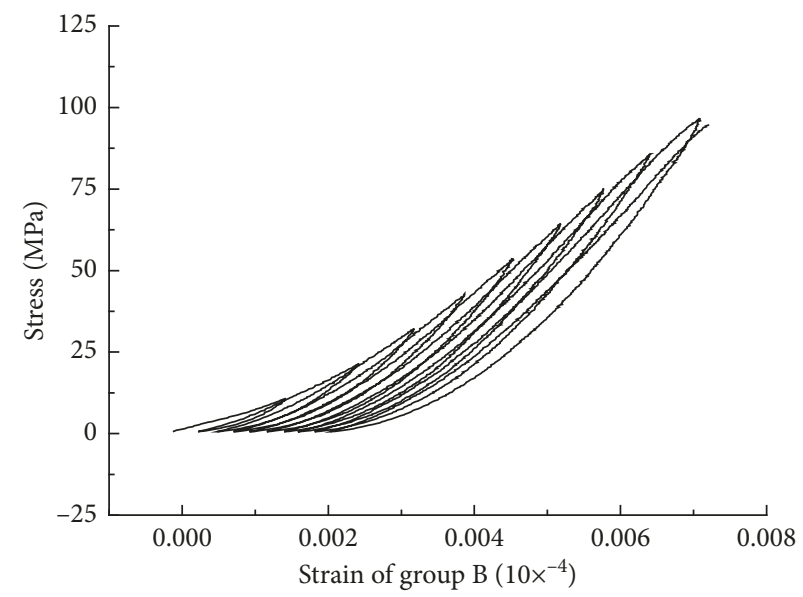

Figure 3: Curve of stress and strain of cycle loading and unloading.

same cycle, and the unloading curve and the reloading curve are also substantially noncoincident. The loading and unloading curves form a hysteresis loop. The first hysteresis loop is not closed, and a large residual deformation occurs between the two curves. The distribution of the hysteresis 
curve is relatively thin at the beginning. But as the cycles increase, the hysteresis loop is increasingly dense and moves toward the direction of the axial strain increasing. The hysteresis loops are pointed rather than elliptical at the load reversal, indicating that the elastic deformation response of the rock sample is rapid and the plastic deformation is small.

During the process of cyclic loading and unloading, the area of the hysteresis loop formed indirectly indicates the degree of the rock microcracks opening and closing under cyclic loading. The larger the area, the more the energy is dissipated inside the rock, and the greater the fatigue damage caused by the cyclic load.

Through the integral operation of the stress-strain curve, the hysteresis energy of the rock sample under the condition of each cycle loading and unloading is obtained, as shown in Table 1:

$$
\Delta U_{i}=\int_{\varepsilon_{i 1+}}^{\varepsilon_{i 2+}} \sigma_{1} \mathrm{~d} \varepsilon_{1}-\int_{\varepsilon_{i 2-}}^{\varepsilon_{i 1-}} \sigma_{1} \mathrm{~d} \varepsilon_{1},
$$

where $\Delta U_{i}$ is the ith cycle hysteresis energy, $\varepsilon_{i 1+}\left(\varepsilon_{i 2+}\right)$ is the axial strain at the beginning and end of the loading process, $\varepsilon_{i 1-}\left(\varepsilon_{i 2-}\right)$ is the axial strain at the beginning and end of the unloading process, and $\sigma_{1}\left(\varepsilon_{1}\right)$ is the axial stress (axial strain).

According to the data in Table 1, the hysteresis energy increases generally with the increase of the loading load, showing a linear growth trend, as shown in Figure 4.

Each loading and unloading cycle will produce the corresponding hysteresis energy, and it accumulates continuously with the increase of the cycles. Eventually, it reaches the ultimate strength of the rock, causing the irreversible deformation and failure:

$$
\Delta U=\sum_{1}^{i} \Delta U_{i}
$$

where $\Delta U$ is the cumulative hysteresis energy.

The relationship between the cumulative hysteresis energy and the cycles during loading and unloading is shown in Figure 5(a). According to the fitting analysis, the cumulative hysteresis energy is exponentially related to the cycles, as shown in Figure 5(b).

\subsection{Elasticity Modulus and Strength Characteristics.} According to the stress-strain curve, the corresponding elastic modulus in the process of cyclic loading and unloading is obtained, as shown in Table 2.

For the convenience of analysis, the data in Table 2 are plotted as a curve of elastic modulus and cycles, as shown in Figure 6. As can be seen from Figure 6, the elastic modulus generally shows an increasing trend. And during each loading and unloading cycle, the increases of the elastic modulus are different.

Assume $\left(E_{1}, E_{2}\right)$ is an interval of elasticity modulus and $E_{1}<E_{2}$, then the findings are as follows:

(1) When the elastic modulus $E<E_{1}$, it increases successively. In each cycle, the unloading elastic modulus is always greater than the loading elastic
TABLE 1: Hysteresis energy in every cycle $\left(\mathrm{MJ} / \mathrm{m}^{3}\right)$.

\begin{tabular}{lcccc}
\hline Group cycles & $\mathrm{A}$ & $\mathrm{B}$ & $\mathrm{C}$ & $\mathrm{D}$ \\
\hline 1 & 0.00322 & 0.00328 & 0.00199 & 0.00261 \\
2 & 0.00721 & 0.00664 & 0.00559 & 0.00584 \\
3 & 0.01108 & 0.01187 & 0.00928 & 0.00974 \\
4 & 0.01485 & 0.01375 & 0.01273 & 0.01373 \\
5 & 0.01921 & 0.0184 & 0.0182 & 0.0105 \\
6 & 0.022 & 0.02276 & 0.02126 & 0.02279 \\
7 & 0.02631 & 0.02639 & 0.02429 & 0.02605 \\
8 & 0.03292 & 0.03448 & 0.02899 & 0.03377 \\
9 & 0.04261 & 0.04637 & 0.09922 & 0.07983 \\
10 & - & - & 0.0474 & 0.06978 \\
\hline
\end{tabular}

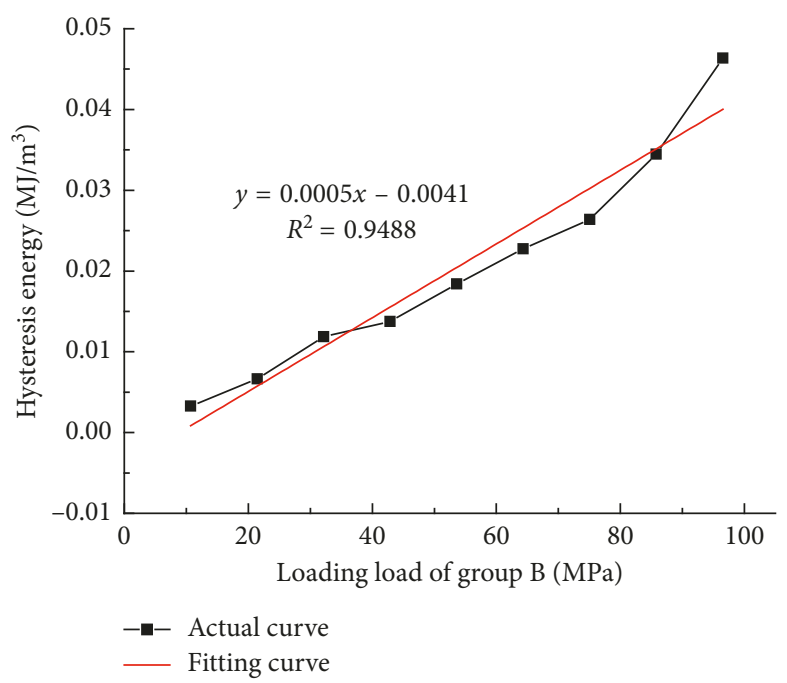

FIGURE 4: Curve of hysteresis energy and stress of loading.

modulus. Moreover, the elastic modulus of the next cycle is greater than the one of the previous cycle. That is, the reloading elastic modulus is greater than the unloading modulus elasticity.

(2) When the elasticity modulus $E>E_{2}$, the reloading elastic modulus is smaller than the unloading elastic modulus.

Due to the difference of rock itself and external factors, it is difficult to determine the critical value. Only a range of 14.3-16.1 GPa can be provided as a reference in the test.

In order to more accurately describe the variation trend of the respective elastic modulus in the stage of loading and unloading, the response ratio theory of loading and unloading is introduced. The response ratio theory of loading and unloading [17] is a new theory for studying the prediction of instability in nonlinear systems. The response ratio of loading and unloading $Y$ is a parameter that quantitatively reflects the instability degree of the nonlinear system. It is defined as

$$
Y=\frac{X_{+}}{X_{-}}
$$

where $X_{+}$is the loading response rate and $X_{-}$is the unloading response rate. 


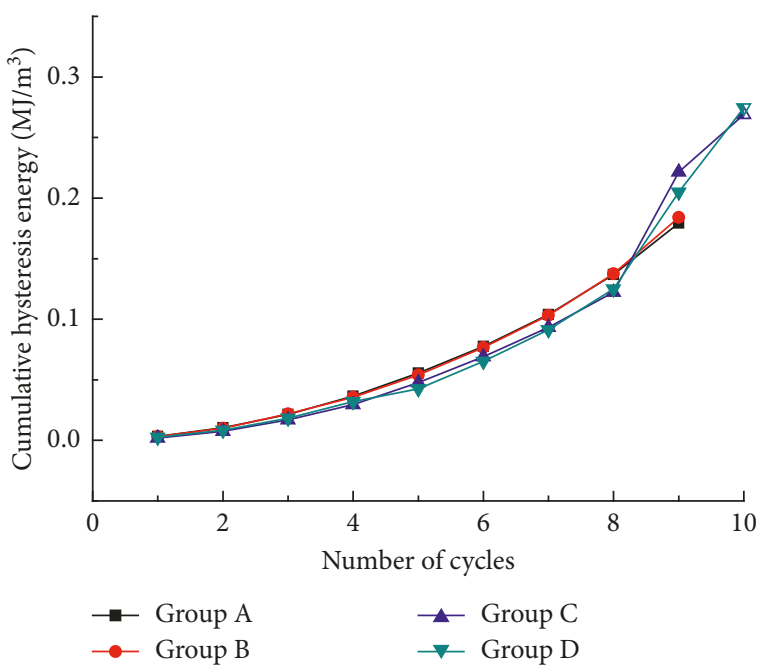

(a)

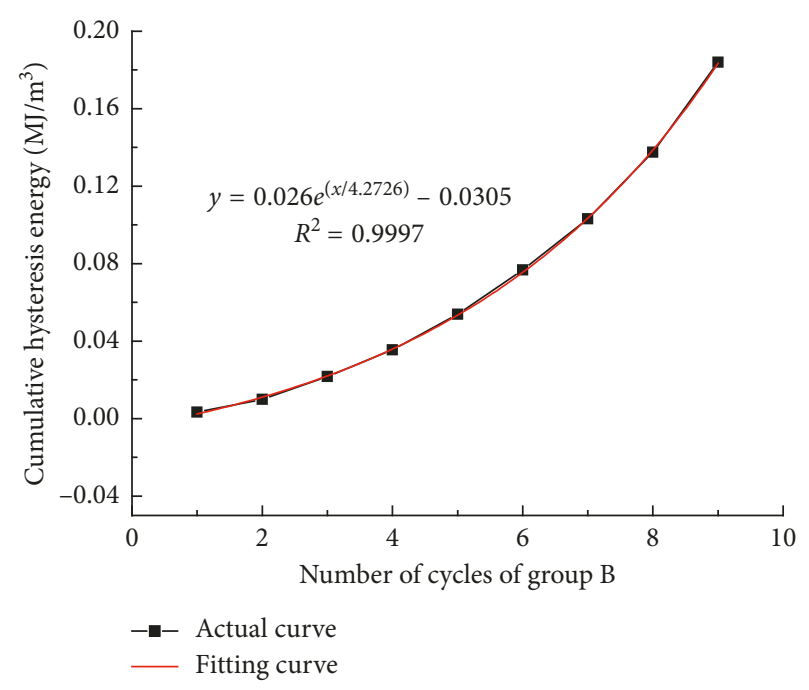

(b)

Figure 5: Curve of cumulative hysteresis energy and cycles.

TABLE 2: Elasticity modulus of loading and unloading (GPa).

\begin{tabular}{lcccc}
\hline & Group A & Group B & Group C & Group D \\
\hline D1 & 6.80 & 6.40 & 8.36 & 7.58 \\
U2 & 9.43 & 8.79 & 9.94 & 9.76 \\
D3 & 9.82 & 9.81 & 11.11 & 10.44 \\
U4 & 11.90 & 11.63 & 12.82 & 12.25 \\
D5 & 12.43 & 12.55 & 13.51 & 12.83 \\
U6 & 14.32 & 14.05 & 15.54 & 14.76 \\
D7 & 14.31 & 14.39 & 15.38 & 14.58 \\
U8 & 16.33 & 16.12 & 17.22 & 16.50 \\
D9 & 16.01 & 16.05 & 16.72 & 16.12 \\
U10 & 17.95 & 17.87 & 18.78 & 18.09 \\
D11 & 17.44 & 17.37 & 18.07 & 17.35 \\
U12 & 19.40 & 19.20 & 20.26 & 19.20 \\
D13 & 18.65 & 18.70 & 19.34 & 18.50 \\
U14 & 20.16 & 20.33 & 21.10 & 20.06 \\
D15 & 19.55 & 19.54 & 20.28 & 19.35 \\
U16 & 21.14 & 21.18 & 21.76 & 21.03 \\
D17 & 20.24 & 20.34 & 20.99 & 20.10 \\
U18 & 21.44 & 21.55 & 22.54 & 21.44 \\
D19 & 20.41 & 20.39 & 21.62 & 20.43 \\
U20 & - & - & 22.69 & 21.15 \\
D21 & - & - & 21.57 & 19.46 \\
\hline
\end{tabular}

The response rate can be defined as

$$
X=\lim _{\Delta \sigma \longrightarrow 0} \frac{\Delta \varepsilon}{\Delta \sigma},
$$

where $\Delta \varepsilon$ and $\Delta \sigma$ are the increments corresponding to the strain and the stress.

When the response ratio of loading and unloading $Y$ is close to 1 , it indicates that the rock sample is relatively stable. When it changes sharply, the rock sample approaches the critical point of failure. Formula (3) can be rewritten as

$$
Y=\frac{X_{+}}{X_{-}}=\frac{E_{-}}{E_{+}} .
$$

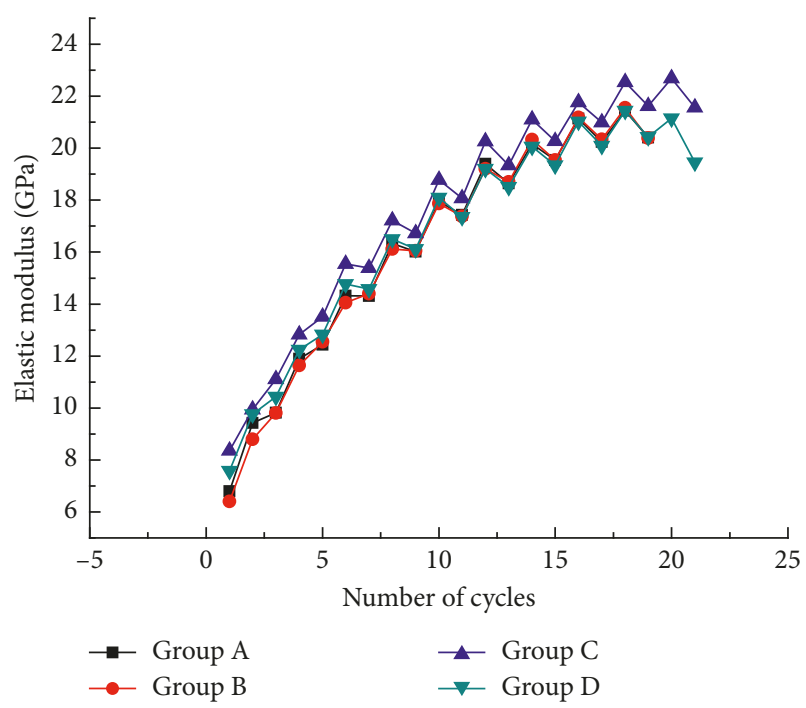

Figure 6: Curve of elasticity modulus of loading and unloading and cycles.

The data in Table 2 are substituted into Formula (5) for verification, and the curve of the response rate of loading and unloading and cycles is plotted, as shown in Figure 7.

It can be seen from Figure 7 that when the rock sample is loaded for the first time, the response rate of loading and unloading is the largest, which is 1.37 (appearing group B). As the cycles increase, the response rate of loading and unloading decreases slowly and tends to 1 , indicating that there is no obvious local damage inside the rock sample during the test stage. Therefore, the change of the elastic modulus of the cyclic loading and unloading is curve-fitted. As shown in Figure 8, the elastic modulus and the cycles show a logarithmic relationship. Under the cyclic loading and unloading action, the elastic modulus of the rock sample 


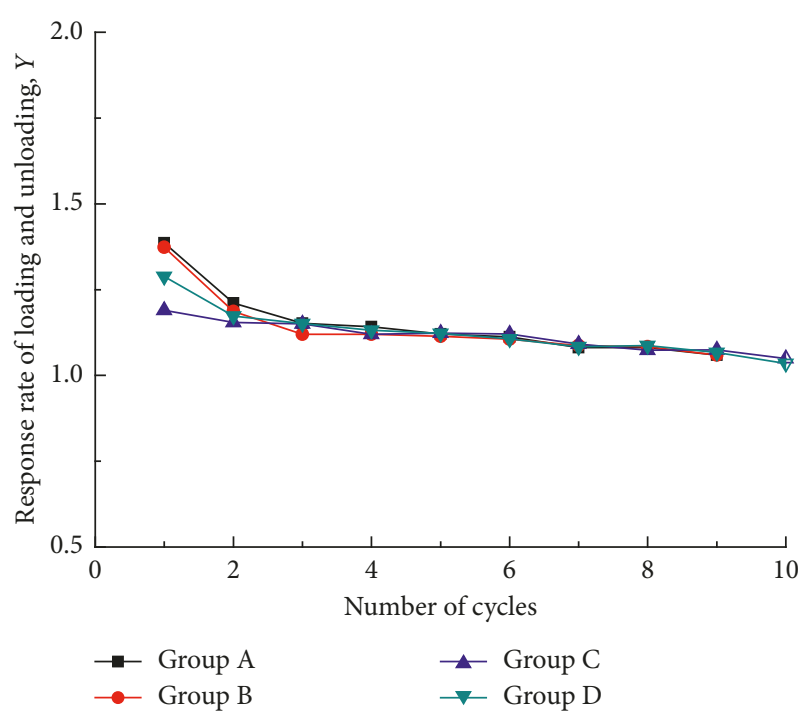

FIGURE 7: Curve of the response ratio of loading and unloading and cycles.

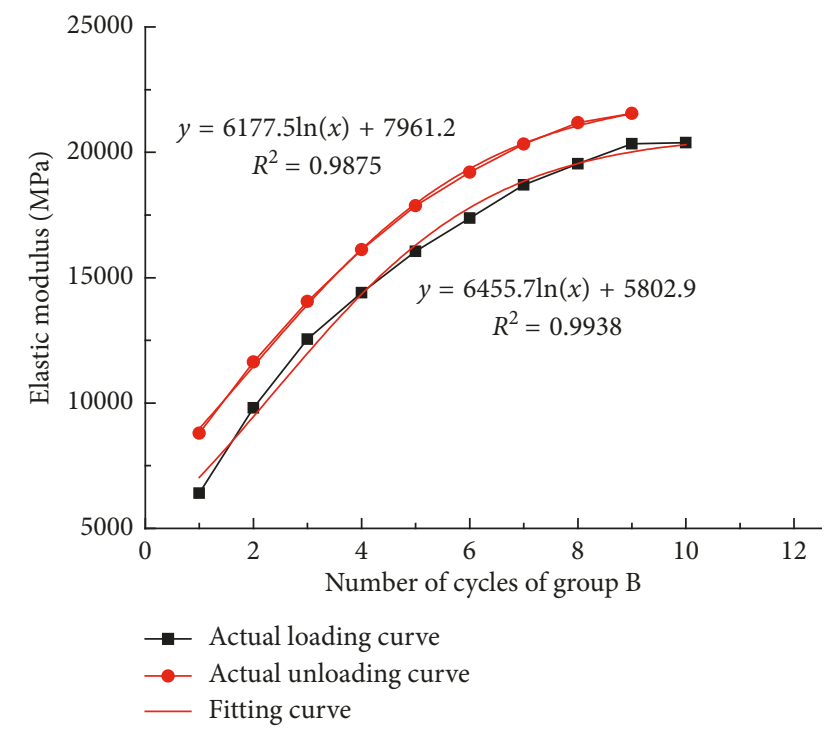

Figure 8: Curve of elasticity modulus and cycles.

has experienced an initial rapid increase and then a slow increase.

Because the rock sample showed no signs of deformation and failure during the test, only partial new cracks were formed under the loading action, and some debris were produced for shear slip at the crack interface. Under the unloading action, the structure of the new crack could be recovered and readjusted, and the debris filling effect makes the new cracks close quickly when reloading. Besides, the frictional strength among the crack faces improves. Thus, the elastic modulus and the overall yield strength of the rock sample were increased [13]. It can be seen that the process of cyclic loading and unloading has a strengthening effect on the rock sample, and with the cycles increasing, the strengthening effect is gradually enhanced.

\section{Conclusions}

Through the test analysis of the uniaxial cyclic loading and unloading, the following conclusions are obtained:

(1) During the process of cyclic loading and unloading, the curves of loading and unloading do not coincide, and a sharp-leaf hysteresis loop is formed. The hysteresis curve distribution is densely changed with the increase of the cycles and moves toward the direction of the strain increasing.

(2) The area of the hysteresis loop characterizes the damage degree inside the rock, and the cyclic hysteresis energy increases linearly with the loading load. The cumulative hysteresis energy increases exponentially with the cycles. The greater the $\mathrm{cu}-$ mulative hysteresis energy is, the more serious the deformation and failure of the rock are.

(3) Under the action of cyclic loading and unloading, the elastic modulus generally increases, and the unloading elastic modulus is greater than the loading elastic modulus in each cycle. Moreover, the elastic modulus of loading and unloading is logarithmically related to the cycles.

(4) The cyclic loading and unloading has a strengthening effect on the rock sample without obvious damage inside, and it gradually increases with the cycles.

\section{Data Availability}

The data used to support the findings of this study are included within the article.

\section{Conflicts of Interest}

The authors declare that there are no conflicts of interests regarding the publication of this paper.

\section{Acknowledgments}

This paper was supported by "Priority Academic Program Development of Jiangsu Higher Education Institutions" and "the Fundamental Research Funds for the Central Universities (2017XKQY044).”

\section{References}

[1] J. Liu, H. Xie, J. Xu et al., "Experimental study on damping characteristics of rock under cyclic loading," Chinese Journal of Rock Mechanics and Engineering, vol. 27, no. 4, p. 712, 2008.

[2] J. Xu, X. Xian, H. Wang et al., "Experimental study on rock deformation characteristics under cycling loading and unloading conditions," Chinese Journal of Rock Mechanics and Engineering, vol. 25, pp. 3040-3045, 2006.

[3] J. Xu, X. Yang, H. Wang et al., "Evolution law of hysteresis curve of rock under cyclic loading," Journal of Southwest Jiaotong University, vol. 40, no. 6, pp. 754-758, 2005.

[4] Y. Yang, Y. Song, and J. Chu, "Experimental study on characteristics of strength and deformation of coal under cyclic loading," Chinese Journal of Rock Mechanics and Engineering, vol. 26, no. 1, p. 201, 2007. 
[5] D. Xi, Y. Xue, and X. Wan, "The damage of saturated sandstones under cyclic loading," Computing Techniques for Geophysical and Geochemical Exploration, vol. 26, no. 3, pp. 193-198, 2004.

[6] C. Su and S. Yang, "Experimental study on deformation and strength characteristics of rock specimens under cyclic loading and unloading," Journal of Hehai University, Natural Sciences, vol. 34, no. 6, pp. 667-671, 2006.

[7] J. Xu, P. Zhang, and N. Li, "Deformation properties of rock mass with intermittent cracks under cyclic loading," Chinese Journal of Geotechnical Engineering, vol. 30, no. 6, pp. 802806, 2008.

[8] M. N. Bagde and V. Petros, "Fatigue properties of intact sandstone samples subjected to dynamic uniaxial cyclical loading," International Journal of Rock Mechanics and Mining Sciences, vol. 42, no. 2, pp. 237-250, 2005.

[9] E. Eberhardt, D. Stead, and B. Stimpson, "Quantifying progressive pre-peak brittle fracture damage in rock during uniaxial compression," International Journal of Rock Mechanics and Mining Sciences, vol. 36, no. 3, pp. 361-380, 1999.

[10] E. Eberhardt, D. Stead, B. Stimpson, and R. S. Read, "Identifying crack initiation and propagation thresholds in brittle rock," Canadian Geotechnical Journal, vol. 35, no. 2, pp. 222-233, 1998.

[11] M. You, "Strength and deformation of rock under complex loading path," Chinese Journal of Rock Mechanics and Engineering, vol. 21, no. 1, pp. 23-28, 2002.

[12] M. You and C. Su, "Experimental study of strengthening of marble specimen in cyclic loading of uniaxial or pseudotriaxial compression," Chinese Journal of Solid Mechanics, vol. 29, no. 1, pp. 66-72, 2008.

[13] S. Xu, X. Feng, and B. Chen, "Experimental study of skarn under uniaxial cyclic loading and unloading test and acoustic emission characteristics," Rock and Soil Mechanics, vol. 30, no. 10, pp. 2929-2934, 2009.

[14] B. Wang, J. Zhu, A. Wu et al., "Experimental study of mechanical properties of Jinping marble under loading and unloading stress paths," Chinese Journal of Rock Mechanics and Engineering, vol. 27, no. 10, pp. 2138-2145, 2008.

[15] Y. Yang, Y. Song, and J. Chu, "Experimental study of characteristics of strength and deformation of coal under cyclic loading," Chinese Journal of Rock Mechanics and Engineering, vol. 26, no. 1, pp. 201-205, 2007.

[16] H. Xie, J. He, and J. Xu, "Deformation characteristics of rock under loading and unloading conditions and experimental study of mechanical parameters," Chinese Journal of Geotechnical Engineering, vol. 25, no. 3, pp. 336-338, 2003.

[17] S. Miao, S. Fan, M. Cai, and C. Chen, "Dynamic characteristics experiment study of loading rock based on theory of load/ unload response ratio," Journal of China Coal Society, vol. 34, no. 3, pp. 329-332, 2009. 


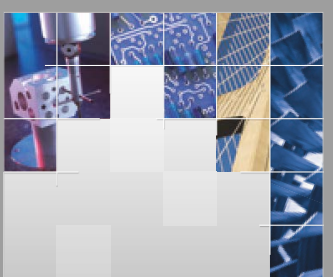

\section{Enfincering}
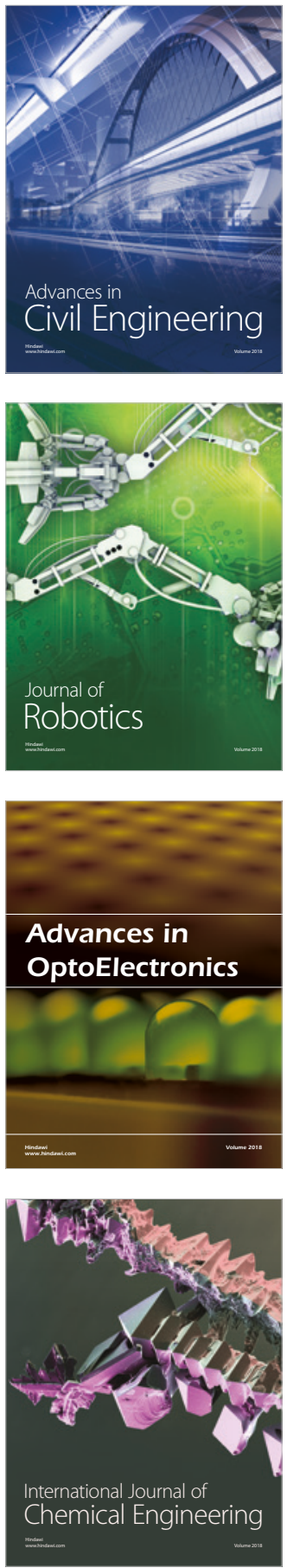

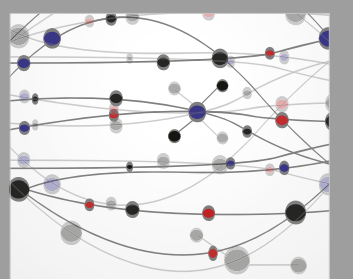

\section{Rotating \\ Machinery}

The Scientific World Journal

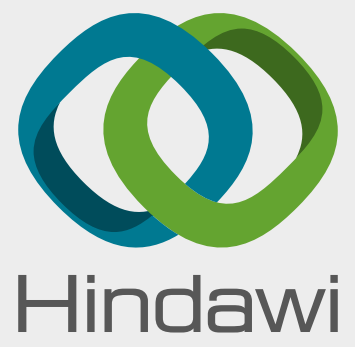

Submit your manuscripts at

www.hindawi.com
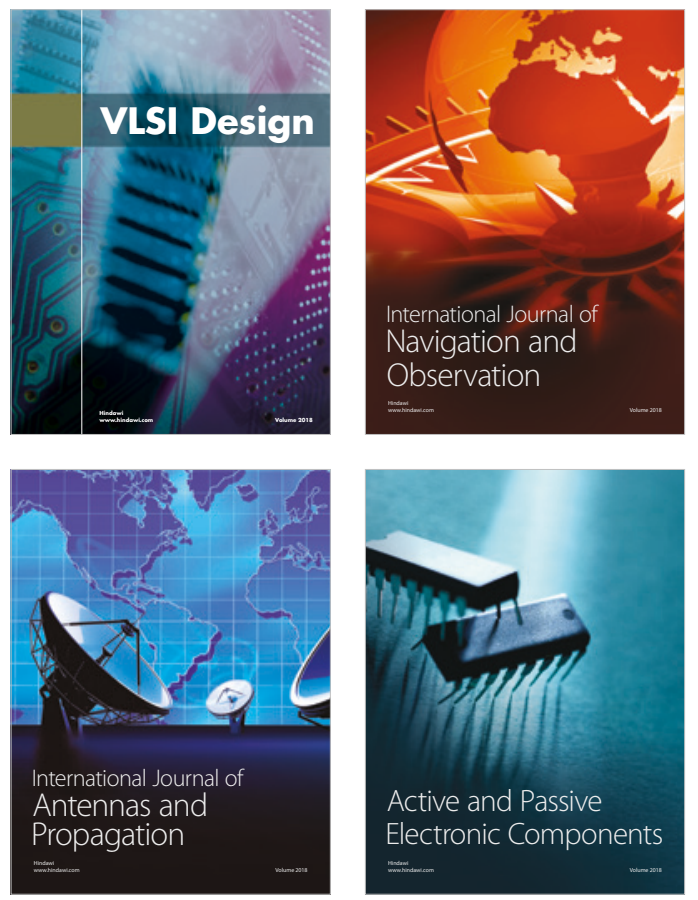
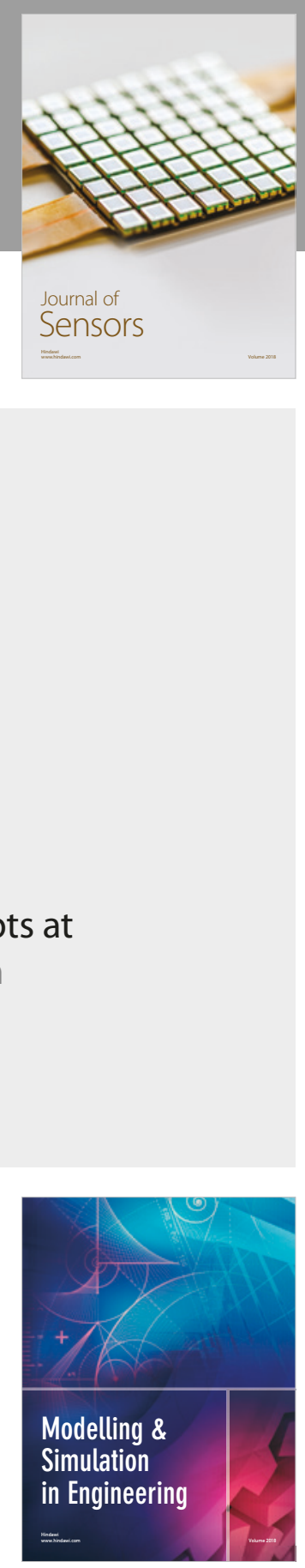

\section{Advances \\ Multimedia}
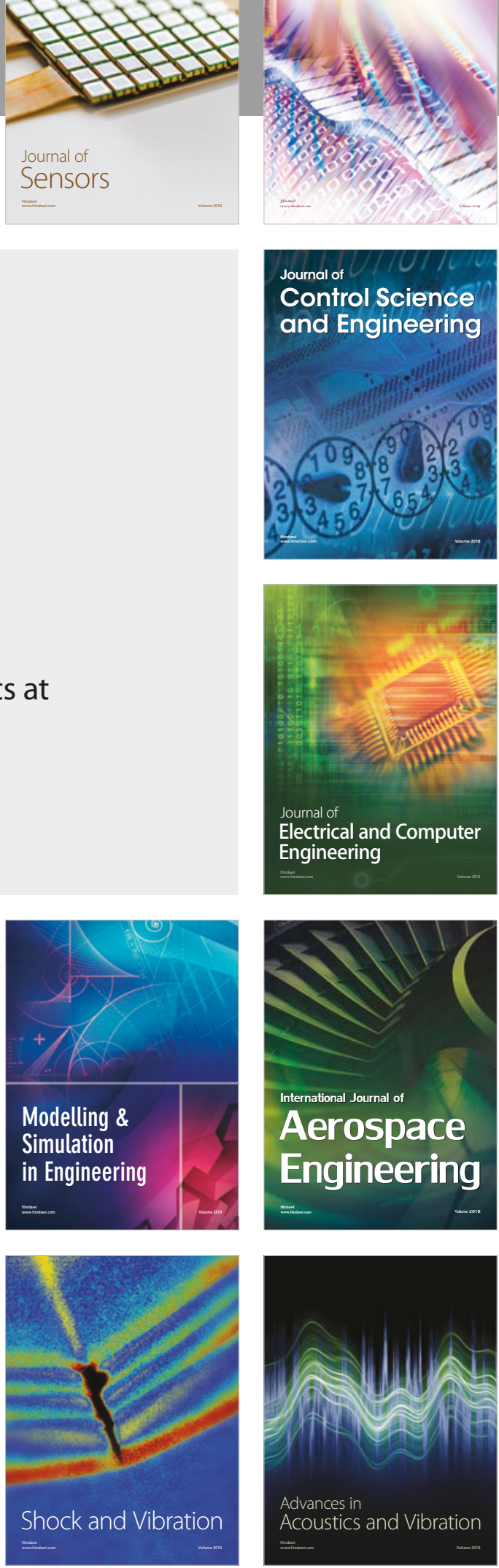